\title{
BMJ Open Consequences of early life exposure to the 1983-1985 Ethiopian Great Famine on cognitive function in adults: a historical cohort study
}

\author{
Getachew Arage (D) , ${ }^{1}$ Tefera Belachew, ${ }^{2}$ Mubarek Abera, ${ }^{3}$ Fedilu Abdulhay, ${ }^{4}$ \\ Misra Abdulahi, ${ }^{5}$ Kalkidan Hassen Abate $^{2}$
}

To cite: Arage G, Belachew T, Abera $\mathrm{M}$, et al. Consequences of early life exposure to the 1983-1985 Ethiopian Great Famine on cognitive function in adults: a historical cohort study. BMJ Open 2020;10:e038977. doi:10.1136/ bmjopen-2020-038977

- Prepublication history for this paper is available online. To view these files, please visit the journal online (http://dx.doi. org/10.1136/bmjopen-2020038977).

Received 02 April 2020 Revised 22 June 2020 Accepted 11 August 2020
D) Check for updates

(c) Author(s) (or their employer(s)) 2020. Re-use permitted under CC BY-NC. No commercial re-use. See rights and permissions. Published by BMJ.

For numbered affiliations see end of article.

\section{Correspondence to}

Mr. Getachew Arage; getachewarage2004@gmail. com

\section{ABSTRACT}

Objectives To investigate the association between early life famine exposure and cognitive function in adults.

Design Historical cohort study

Setting North Wollo Zone, Northeast Ethiopia.

Participants We recruited 1047 adult men and women aged 30-38 years who had history of early life exposure to Ethiopian great famine. Based on self-reported age and birth date, participants were categorised into famine exposed in early life (prenatal/postnatal) and non-exposed groups.

Outcome measures The primary outcome measure of this study was cognitive function in adults after early life exposure to famine. Cognitive function was measured using Montreal Cognitive Assessment-basic. Associations between exposure and outcome variables were examined by linear regression analysis models.

Results Adjusted for covariates, early life exposure to famine showed 1.29 ( $\beta=-1.29 ; 95 \% \mathrm{Cl}-2.16$ to -0.52$)$ points lower cognitive function score compared with non-exposed. Based on subanalysis for timing of famine exposure, postnatal exposure to famine resulted in 2.26 ( $\beta=-2.26 ; 95 \% \mathrm{Cl}-3.12$ to -1.36$)$ points lower cognitive function score compared with non-exposed groups. Prenatal famine exposure had $1.26(\beta=-1.26 ; 95 \% \mathrm{Cl}$ -2.35 to 0.94 ) points lower cognitive function score although not statistically significant.

Conclusions Famine exposure in early life was associated with cognitive functions in adults. While the overall findings highlight the importance of optimal nutrition in early life for brain growth and development, the association observed between postnatal famine exposure and adult cognitive function may indicate the relative importance of learning and experience during early childhood for optimal brain development after birth. Further studies are needed to elucidate the potential mechanism behind this association.

\section{INTRODUCTION}

Cognitive functions are a complex sets of higher mental activities controlled by the brain, and includes attention, memory, thinking, learning and perception. ${ }^{12}$ Rapid growth and development of the human brain (brain growth spurt) occur during fetal and early postnatal (first 2 years of age) life. At
Strengths and limitations of this study

- This is the first study to examine the effect of early life famine exposure on adulthood cognitive function in low-income country, Ethiopia.

- To control for selection bias, a 1-year transitional (washout) period was considered.

- Severity of exposure at individual level was not considered.

- Early childhood experiences, parent-child bond and health status during early life did not considered.

- Birth weight and maternal factors including behavioural risk factors, psychological stress and infection did not considered.

birth, the brain already grown its $25 \%$ of adult size, and by the age of 2-3 years it grows $80 \%$ of its adult size. ${ }^{34}$ As such, the growth and subsequent functions of the brain can greatly be influenced by prenatal and postnatal environments such as malnutrition and other adverse life experiences. ${ }^{5}$ Nutrients are essentials for the formation of the building blocks of neurotransmitters, cell proliferation, DNA synthesis and enzymes in the brain. ${ }^{1}$ Malnutrition in the postnatal period affects child's ability to interact and explore with the environment which interferes with language, motor and social skills development; all of which are the foundation block for adult cognitive capacities. ${ }^{56}$

Currently the burden of neurological and mental health disorders are alarmingly increasing, particularly, with a higher pace in sub-Saharan African countries. ${ }^{78}$ According to the 2016 Global Burden of Disease report, neurological disorders were the leading cause of Disability-Adjusted Life Years. ${ }^{9}$ In Ethiopia, high prevalence of cognitive impairment was observed among adults living with underlying medical disorders such as HIV/AIDS, and diabetes mellitus. ${ }^{10-12}$ 
Early scientists Barker et al introduced a theory called 'Fetal Origin of Adult Diseases' or 'Developmental Origins of Health and Disease' to explain the long-term consequences of early life undernutrition on adult health and diseases such as cognitive function. ${ }^{13-15}$

Famine study provides an opportunity to examine the association between early life nutrition and its long-term effects on adult diseases including cognitive function. Previous famine studies have contributed substantial evidence on the association between famine exposure in early life and cognitive function in adults, and reported heterogeneous findings. ${ }^{16-20}$

The 1983-1985 Ethiopian Great Famine was one of Africa's most severe famines that caused over half a million deaths. ${ }^{21} 22$ It affects the whole Ethiopia and returns to normal year (but some problems in certain villages) during September 1986-September 1987. ${ }^{21}$ Hence, we conducted this study to investigate the effects of early life exposure to famine (prenatal and first 2 years of postnatal life) on cognitive function in adults among survivors of the Ethiopian Great famine in Wollo province, Ethiopia.

\section{METHODS AND MATERIALS}

\section{Study setting and design}

The study setting has been described in detail elsewhere. ${ }^{23}$ Briefly, the study was conducted in Raya Kobo District, northeast Ethiopia, which was the epicentre for the 19831985 Ethiopian great famine. ${ }^{21} \mathrm{~A}$ historical cohort study design was employed from 15 March to 30 April 2019.

\section{Study participants and sampling}

Adult men and women aged 30-38 years who had history of early life exposure to famine were the study participants. Self-reported age and birth date were used to categorise famine exposure status. The start and end dates of the famine were used to define windows for famine exposure. ${ }^{21}$ Thus, the study participants were categorised into two groups: early life exposed, age from 34 to 38 years with birth date between 8 September 1981 to 30 August 1985; non-exposed, age from 30 to 32 years with birth date between 8 September 1987 to 8 October 1988. The early life famine exposed groups were further grouped into prenatally exposed, age from 34 to 36 years with birth date between 8 August 1983 to 30 August 1985 and postnatal exposed, age from 37 to 38 years with birth date between 8 September 1981 to 8 August 1983. In order to get optimal washout period between exposed and nonexposed groups, participants born immediately after end of the famine (between 8 September 1986 to 30 August 1987) were excluded from this study (online supplemental file 1). Additionally, adults who were displaced to other area of the country and those who were in other location during the famine and participants with deformity (Kyphosis, Scoliosis and limb deformity) were excluded from the study.

Two population mean formula using G-Power V.3.0.10 and taking type one error $5 \%, 80 \%$ power, a design effect of 1.5 and calculated effect size of 0.1817 was used to calculate the sample size. Assuming the mean $( \pm \mathrm{SD})$ of general cognition score in exposed groups 12.06 (3.50) and nonexposed groups 11.40 (3.76) from a study conducted in China, ${ }^{17}$ the total calculated sample size was 1071 (714 exposed and 357 non-exposed groups). We included 1047 (697 exposed and 350 non-exposed groups) participants who had a complete data on all variables required in the analysis. Multistage stratified random sampling technique was used to select the study participants (figure 1).

\section{Patient and public involvement}

There was no direct public or patient involvement in the design and implementation of this study.

\section{Data collections and measurement}

Pretested and structured questionnaire was used to collect sociodemographic/economic data and lifestyle factors of participants using face-to-face interview. The questionnaire was first prepared in English and then translated into Amharic (the local language) and back into English to ensure consistency. Eight trained clinical nurses collected the data.

\section{Main exposure variable}

The main exposure variable, early life (prenatal and first 2 years of postnatal life) exposure to the 1983-1985 Ethiopian great famine was determined using the age and birth date of participants. We considered the participants is prenatal exposed (intrauterine life or born during the famine), postnatal exposed (first 2 years of age during the famine) and non-exposed (born after the famine).

\section{Outcome measure}

The primary outcome variable, cognitive function was measured using the Montreal Cognitive Assessment (MoCA)-basic. MoCA enables the assessment of different domains of cognitive function including perception, thinking, reasoning and memory. It has high reliability in individuals who are illiterate and have low-educational status. ${ }^{24}$ The cognitive function score for each item was added to get the total score; then the mean score was computed.

\section{Covariates}

Additionally, various sets of covariates including participants sex, age, educational status, marital status, residence, occupational status, wealth index, dietary pattern, substance use and physical activity were collected. We define household wealth index, substance use and physical activity similar to previous study. ${ }^{23}$ Dietary pattern was assessed using qualitative food frequency questionnaire. Participants were asked to report the frequency of consumption of each food per day, per week or per month using the past 1 year as a reference. ${ }^{25}$ Two major dietary patterns, healthy and unhealthy, were derived through K-means cluster analysis. The detail for assessing dietary patterns has been described as supplementary file (online supplemental file 2). History of raised blood 
pressure and diabetes was assessed by interviewing adults. Body mass index (BMI) was calculated as the weight in kilogram divided by height in metres squared $\left(\mathrm{kg} / \mathrm{m}^{2}\right)$. Blood pressure was measured in triplicate using digital blood pressure measurement after 5 min of rest. Sex of the participants and residency were considered as potential effect modifiers.

\section{Statistical analysis}

The data were doubly entered to Epidata V.3.1 and exported to SPSS V.25 (SPSS) for analysis. Percentages were used to described categorical variables while mean and \pm SD or medians and IQRs were used to described continuous variables. Differences in mean cognitive function score among different groups of early life was compared using one-way and two-way analysis of variance or t-test.
A series of linear regression analyses with robust statistical procedures were conducted to evaluate association between the three exposure categories (early life, prenatal or postnatal exposure) and cognitive function in adults. The estimate ( $\beta$-coefficients) and $95 \%$ CI were reported to describe the associations. Three sets of regression models were developed. Model 1: included the outcome and the main exposure variable (famine exposure status). Model 2: built on model one by adding sex, age, residence and educational status. Model 3: full adjusted model built on model two by adding BMI, dietary pattern, increased blood pressure, physical activity, cigarette smoking, alcohol drinking, history of hypertension, diabetes and effect modifiers. The rationale of the different models was to observe changes in the association between the main exposure and outcome variable when different sets
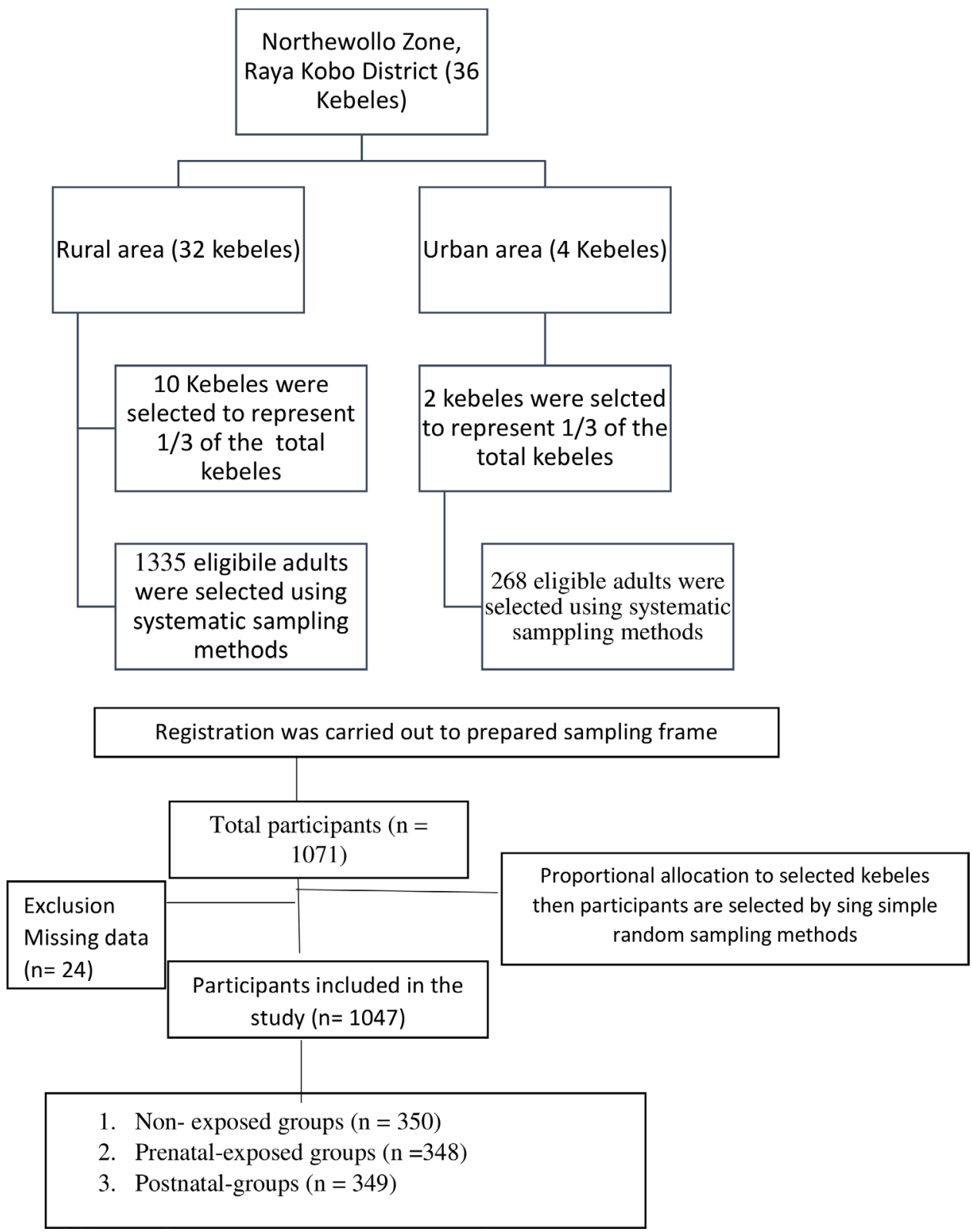

Figure 1 Flow diagram representing sample recruitment. 
Table 2 Distribution of cognitive test score by famine exposure status, sex of participant and residency, Northeast Ethiopia, $2019(n=1047)$

\begin{tabular}{llllll}
\hline Variables & $\begin{array}{l}\text { Early life } \\
\text { exposed }^{*}\end{array}$ & $\begin{array}{l}\text { Prenatal } \\
\text { exposed }\end{array}$ & $\begin{array}{l}\text { Postnatal } \\
\text { exposed }\end{array}$ & Non-exposed & P value \\
\hline $\begin{array}{l}\text { Cognitive test score, mean } \pm \text { SD } \\
\text { Sex }\end{array}$ & $17.95 \pm 7.43$ & $19.43 \pm 6.60$ & $16.48 \pm 6.70$ & $21.11 \pm 6.90$ & $<0.001$ \\
$\quad$ Female & & & & & \\
$\quad$ Male & $16.61 \pm 7.50$ & $18.70 . \pm 6.42$ & $14.53 \pm 7.94$ & $18.37 \pm 7.24$ & 0.031 \\
$\quad$ Residence & $19.93 \pm 6.87$ & $20.48 . \pm 6.74$ & $19.36 \pm 7.02$ & $23.67 \pm 5.41$ & \\
$\quad \begin{array}{l}\text { Urban } \\
\text { Rural }\end{array}$ & $18.53 \pm 6.92$ & $19.48 \pm 6.62$ & $17.57 \pm 7.12$ & $21.47 \pm 6.81$ & 0.673 \\
\hline
\end{tabular}

${ }^{*}$ Prenatal and postnatal exposed, p value-represents Independent samples t-tests or two-way analysis of variance for continuous variables.

of covariates were accounted in the model. The outcome variable, cognitive function score was tested for normality using a P-P plot and a steam leaf diagram, and all potential confounders were tested for linearity with the outcome variable using scatter plots. Effect modification by sex and residence was assessed by including interaction terms for both famines exposed groups. $\mathrm{P}$ values presented were based on two-tailed test and $\mathrm{p}<0.05$ was considered statistically significant.

\section{RESULTS}

\section{Background characteristics}

A total of 1047 participants (697 exposed and 350 nonexposed groups) were enrolled to the study. The mean $( \pm$ SD) ages for early life exposed and non-exposed groups were $36.30( \pm 1.5)$ and $31.2( \pm 0.6)$, respectively. Four hundred fifteen $(59.5 \%)$ of the participants were women exposed to famine. Five hundred fifty-eight $(80.1 \%)$ of the participants were rural residents exposed to famine. Three hundred three $(43.5 \%)$ of them cannot read and write among early life exposed groups (table 1 ).

\section{Cognitive function}

The mean $( \pm \mathrm{SD})$ cognitive function score among early life exposed and non-exposed groups was $17.95 \pm 7.43$ and $21.11 \pm 6.90$, respectively. Based on the time of exposure to famine, the mean cognitive function score for prenatal and postnatal exposed group was $19.43 \pm 6.60$ and $16.48 \pm 6.70$, respectively. Among early exposed groups, the mean cognitive test score was $16.61 \pm 7.50$ for women and $19.93 \pm 6.87$ for men whereas it was $18.53 \pm 6.92$ for urban and $15.65 \pm 8.84$ for rural residents (table 2).

\section{Early life famine exposure and cognitive function in adults}

Multivariable linear regression analysis was used to detect the association between cognitive function and the famine exposure in early life (table 3 ). After adjusted for the main exposure variable (model 1), the cognitive function score in early life, prenatal and postnatal exposed groups was lowered by 3.16 ( $\beta=-3.16 ; 95 \%$ CI -4.09 to $-2.28), 1.68(\beta=-1.68 ; 95 \%$ CI -2.74 to -0.62$)$ and 4.66 $(\beta=-4.66 ; 95 \%$ CI -5.76 , to -3.55$)$ points, respectively, compared with non-exposed groups. After adjusted for sex, age, residence and educational status (model 2), the

Table 3 Associations between early life famine exposure and cognitive function in adults, North Wollo Zone, Northeast Ethiopia, 2019

\begin{tabular}{llccl}
\hline Models & Early life exposed & Prenatal exposed & Postnatal exposed & Non-exposed \\
\hline Model 1 & $-3.16(-4.09$ to -2.28$)$ & $-1.68(-2.74$ to -0.62$)$ & $-4.66(-5.76$ to -3.55$)$ & Ref. \\
\hline $\mathrm{R}^{2}$ (adjusted) & 0.04 & 0.02 & 0.08 & Ref. \\
\hline Model 2 & $-1.12(-1.89$ to -0.33$)$ & $-1.27(-2.27$ to -0.12$)$ & $-2.18(-3.11$ to -1.27$)$ & Ref. \\
$\mathrm{R}^{2}$ (adjusted) & 0.36 & 0.35 & 0.42 & Ref. \\
Model 3 & $-1.29(-2.16$ to -0.52$)$ & $-1.26(-2.35$ to 0.94$)$ & $-2.26(-3.12$ to -1.36$)$ & Ref. \\
$\mathrm{R}^{2}$ (adjusted) & 0.37 & 0.36 & 0.45 & Ref.
\end{tabular}

Data are $\beta$-coefficients $(95 \% \mathrm{Cl})$ from multiple linear regression analysis.

All $\beta$-coefficients are related to the non-exposed groups.

Model 1: cognitive test score with famine exposure (unadjusted for any covariate).

Model 2: adjusted for sex, age, residence and educational status.

Model 3: adjusted for body mass index, dietary pattern, increased blood pressure, physical activity, cigarette smoking, alcohol drinking,

history of chronic diseases and effect modifiers.

*Prenatal and postnatal exposed, Ref-reference. 
Table 1 Background characteristics of the study participants according to Ethiopian famine exposure status, North Wollo Zone, Northeast Ethiopia, 2019 ( $n=1047)$

\begin{tabular}{|c|c|c|c|c|c|}
\hline Variables & $\begin{array}{l}\text { Early life } \\
\text { exposed } \\
\mathrm{n}=697\end{array}$ & $\begin{array}{l}\text { Prenatal } \\
\text { exposed group } \\
n=348\end{array}$ & $\begin{array}{l}\text { Postnatal } \\
\text { exposed } n=349\end{array}$ & $\begin{array}{l}\text { Non-exposed } \\
\text { group } \\
n=350\end{array}$ & $P$ value \\
\hline Age (years), mean $\pm S D$ & $36.3 \pm 1.5$ & $35.05 \pm 0.8$ & $37.62 \pm 0.5$ & $31.20 \pm 0.6$ & $<0.001 \dagger$ \\
\hline \multicolumn{6}{|l|}{ Sex, n (\%) } \\
\hline Female & $415(59.5 \%)$ & $205(58.9 \%)$ & $210(60.2 \%)$ & $169(48.3 \%)$ & \multirow[t]{2}{*}{$0.002 \dagger$} \\
\hline Male & $282(40.5 \%)$ & $143(41.1 \%)$ & $139(39.8 \%)$ & $181(51.7 \%)$ & \\
\hline \multicolumn{6}{|l|}{ Residence, n (\%) } \\
\hline Urban & $139(19.9 \%)$ & $70(20.1 \%)$ & $69(19.7 \%)$ & $53(15.2 \%)$ & \multirow[t]{2}{*}{0.165} \\
\hline Rural & $558(80.1 \%)$ & $278(79.8 \%)$ & $280(80.3 \%)$ & $297(84.8 \%)$ & \\
\hline \multicolumn{6}{|l|}{ Educational status } \\
\hline Cannot read and write & $303(43.5 \%)$ & $138(39.6 \%)$ & $165(47.3 \%)$ & $87(24.8 \%)$ & \multirow[t]{4}{*}{$<0.001 \dagger$} \\
\hline Primary school & $170(24.4 \%)$ & $86(24.7 \%)$ & $84(24.1 \%)$ & $66(18.8 \%)$ & \\
\hline Secondary school & $129(18.5 \%)$ & $72(20.7 \%)$ & $57(16.3 \%)$ & $116(33.2 \%)$ & \\
\hline Secondary and above & $95(13.6 \%)$ & $52(14.9 \%)$ & $43(12.3 \%)$ & $81(23.2 \%)$ & \\
\hline \multicolumn{6}{|c|}{ Household wealth index, $\mathrm{n}(\%)$} \\
\hline Low & $184(26.4 \%)$ & $76(21.8 \%)$ & $108(30.9 \%)$ & $70(20.0 \%)$ & \multirow[t]{3}{*}{$0.011 \dagger$} \\
\hline Medium & $103(14.7 \%)$ & $55(15.8 \%)$ & $48(13.7 \%)$ & $58(16.6 \%)$ & \\
\hline High & $410(58.8 \%)$ & 217 (62.4\%) & $193(55.4 \%)$ & $222(63.4 \%)$ & \\
\hline \multicolumn{6}{|l|}{ Marital status, n (\%) } \\
\hline Single & $113(15.5 \%)$ & $54(15.5 \%)$ & $59(16.9 \%)$ & $102(29.2 \%)$ & \multirow[t]{3}{*}{$<0.001 \dagger$} \\
\hline Married & $468(67.2 \%)$ & $230(66.1 \%)$ & $238(68.2 \%$ & $220(62.8 \%)$ & \\
\hline Divorced/widowed & $116(17.4 \%)$ & $64(18.4 \%)$ & $52(14.8 \%)$ & 28 (8.0\%) & \\
\hline \multicolumn{6}{|l|}{ Current drinker, n (\%) } \\
\hline Yes & $384(55.1 \%)$ & $220(63.2 \%)$ & $164(46.9 \%)$ & $237(67.7 \%)$ & \multirow[t]{2}{*}{$0.001 \dagger$} \\
\hline No & $313(44.9 \%)$ & $128(36.8 \%)$ & $185(53.1 \%)$ & $113(32.3 \%)$ & \\
\hline \multicolumn{6}{|l|}{ Dietary pattern, n (\%) } \\
\hline Healthy & 202 (28.9\%) & $113(32.4 \%)$ & $89(25.5 \%)$ & $125(35.7 \%)$ & \multirow[t]{2}{*}{$0.012 \dagger$} \\
\hline Unhealthy & 495 (71.1\%) & 235 (67.5\%) & $260(74.5 \%)$ & $225(64.2 \%)$ & \\
\hline \multicolumn{6}{|l|}{ Physical activity level, n (\%) } \\
\hline Low & $55(7.8 \%)$ & $4(1.2 \%)$ & $51(14.6 \%)$ & $6(1.7 \%)$ & \multirow[t]{3}{*}{$<0.001 \dagger$} \\
\hline Moderate & $117(16.8 \%)$ & $40(11.5 \%)$ & 77 (22.1\%) & 28 (8.0\%) & \\
\hline High & 525 (75.4\%) & $304(87.3 \%)$ & $221(63.3 \%)$ & $316(90.3 \%)$ & \\
\hline BMI $\left(\mathrm{kg} / \mathrm{m}^{2}\right)$, mean $\pm \mathrm{SD}$ & $23.3 \pm 4.9$ & $23.06 \pm 5.21$ & $23.36 \pm 4.60$ & $23.3 \pm 4.83$ & $0.025 \dagger$ \\
\hline \multicolumn{6}{|l|}{ History of diabetes mellitus } \\
\hline Yes & 115 (16.5\%) & $15(4.3 \%)$ & $100(28.6 \%)$ & $14(4.0 \%)$ & \multirow[t]{2}{*}{$<0.001 \dagger$} \\
\hline No & 582 (83.5\%) & 333 (95.6\%) & 249 (71.4\%) & 336 (96.0\%) & \\
\hline
\end{tabular}

${ }^{*}$ Prenatal and postnatal exposed, p value-represents Independent samples t-tests for continuous variables or $\chi 2$ test for categorical variables.

† Statistical significance.

BMI, body mass index.

score of cognitive function was lowered by $1.12(\beta=-1.12$; $95 \% \mathrm{CI}-1.89$ to -0.33$), 1.27(\beta=-1.27 ; 95 \% \mathrm{CI}-2.27$ to $-0.12)$ and $2.18(\beta=-2.18 ; 95 \% \mathrm{CI}-3.11$ to -1.27$)$ points in early life, prenatal and postnatal exposed groups, respectively. In the fully adjusted model (model 3), early life exposure to famine showed $1.29(\beta=-1.29 ; 95 \% \mathrm{CI}$
-2.16 to -0.52) points lower cognitive function score compared with non-exposed. Postnatal exposure resulted in 2.26 points reduction $(\beta=-2.26$; $95 \% \mathrm{CI}-3.12$ to -1.36$)$ while prenatal exposure resulted in 1.26point reduction $(\beta=-1.26 ; 95 \%$ CI -2.35 to 0.94$)$ in cognitive function scores although the later was not statistically significant. 
Table 4 Multivariable linear regression model predicting cognitive function of adults in North Wollo Zone, Northeast Ethiopia, 2019

\begin{tabular}{lcrc}
\hline Variables & Early life exposed & Non-exposed & P value \\
\hline Sex of participants (male) & $2.75(1.83$ to 3.67$)$ & Ref. & $<0.001$ \\
\hline Place of residence (rural) & $-1.57(-2.75$ to -0.38$)$ & Ref. & 0.010 \\
Educational status (secondary and above) & $3.15(2.69$ to 3.61$)$ & Ref. & Ref. \\
Dietary pattern (unhealthy) & $-1.84(-2.80$ to -0.88$)$ & Ref. & $<0.001$ \\
History of diabetes mellitus & $-1.13(-2.47$ to -0.204$)$ & 0.09 \\
\hline
\end{tabular}

Adjusted $R^{2}=0.45$, Ref-reference, .

The effect of famine exposure in early life was not modified by sex and residency ( $p$ interaction $>0.05$; results not shown).

\section{Role of covariates}

Different models were used to account for different sets of potential confounders. But, the association between early life famine exposure and adulthood cognitive function continued significant. The highest effect of famine exposure on low cognitive function score $(\beta=-3.16$; $95 \%$ CI -4.09 to to 2.28 ) was observed in unadjusted regression model (table 3). Moreover, male sex and educational status of secondary and above were positively associated cognitive function. Rural residency and unhealthy dietary pattern was negatively associated with cognitive function in adults (table 4 ).

\section{DISCUSSION}

The main goal of this study was to examine the association between early life famine exposure and cognitive function in adults. The focus of this articlewas therefore to describe the contributions of factors beyond early childhood experience and adult lifestyles, which affects cognitive function of adults. ${ }^{2627}$

When examining the association between famine exposure in early life with cognitive function in adults using multivariable linear regression models, adults who had early life exposure to famine were 1.29 points lowered cognitive function score. This association might have been confounded by other predictors of cognitive function in adults. To account for this, we adjusted for potential confounders. However, in all of these adjusted models, the observed association remained significant after adjustment for potential confounders. Based on subanalysis by timing of exposure, we found that adults who had prenatal famine exposure resulted in 1.26 points lowered cognitive function score compared with non-exposed though not statistically significant. Similarly, postnatal exposure to famine had 2.26 points decreased cognitive function score after adjusted for all possible covariates.

Our findings showed that early life exposure to famine negatively affected adult cognitive function. Although much is not known about the mechanisms how early life famine exposure affects cognitive function in adult life, this might be explained by the potential capacity of adverse life experience during early life that could have impaired the growth and development of the brain, which can affect cognitive function across the life span. ${ }^{28}$ In addition, epigenetic changes during early life is another potential mechanism that facilitated to understand the association between famine exposure in early life and the risk of altered cognitive function in adults. ${ }^{29} 30$ In Barbados Nutrition Study, long-lasting DNA methylation changes due to early childhood malnutrition was associated with liability for defective attention and cognition in adults. $^{31}$

The finding that postnatal exposure to famine, but not prenatal exposure was associated with cognitive function in adults can be discussed from the following three perspectives.

First, from the biological point of view, the first 2 years of postnatal life is a period of the fastest brain development compared with other periods, and accompanied by highest energy demands of the brain. ${ }^{3432}$ The frontal lobe, which is the centre for higher cognitive functions including planning, sequencing and self-regulation appears to occur in growth spurts during the first 2 years of life after birth. ${ }^{4}$ The study of Georgieff et al reported that protein-energy malnutrition during the postnatal period resulted in smaller brain size related with fewer neurons, simpler synaptic connections and reduced concentration of neurotransmitters, and growth factors altogether contribute for poorer long-term cognitive outcomes. ${ }^{33}$ Moreover, this might be due to the fact that nutrient supply to the brain might not be affected unlike other organs. As a result, undernutrition during prenatal life could not have a profound effect on cognitive decline in adults. ${ }^{15}$

Second, from the behavioural point of view, malnourishment during the first 2 years of life has been associated with immaturity of the brain likely due to lack of stimulus from deprived environments and lack of opportunity to play, communication and explore to their environment. ${ }^{6}$ Moreover, the mother could not have the capacity to actively engage their young children to play and communication as the mother themselves have affected by the famine. Thus, the lack of opportunity to get engaged and 
to explore the environment as a secondary complication of the malnutrition from famine might rather explain the lower cognitive function in adulthood. Impaired exploratory behaviour and motor development can further compromise and potentiate early damage of the brain. ${ }^{34}$

Third, those children who experienced famine in their postnatal life could have higher risk of stunting. Studies show that stunting in early life is associated with poor cognitive function in later life. ${ }^{35}{ }^{36}$ Furthermore, the implication of sever famine like Ethiopian great famine affects children in early life is not only related with insufficient foods. It also affects the quality of parent-child bond, social development and a child's ability to interact with the environment, which determine cognitive function in the long run. ${ }^{2421}$

In this study, we observed that the scores on the MoCA are all below standard cut-off scores, even in the unexposed group. Therefore, it is important to notice different factors responsible for lower score in the overall population. Ethiopia is known by high burden of stunting among children. ${ }^{37}$ The ability to get adequate nutrition is the most common problem in Ethiopia. Consequently, early childhood stunting is negatively associated with cognitive function in adults. ${ }^{35}$ Moreover, factors such as parental schooling, wealth, size at birth, duration of breast feeding, health problems of early childhood (diarrhoea, malaria, acute respiratory illness, malaria) have impact on cognitive function in later life. All of which could have affected the outcome among the overall populations. ${ }^{238}$

The observed association between early life famine exposure and cognitive function in adults was consistent with studies conducted in the Chinese famine exposed birth cohorts of the year 1959-1961, ${ }^{161720}{ }^{2}$ Dutch famine ${ }^{19}$ and Ghana famine. ${ }^{39}$ The study participants during the Chinese, Ghana and Ethiopian famine were selected from the settings known for chronic malnutrition. The finding that prenatal exposure to famine was not associated with cognitive function is consistent with other Dutch famine study $^{40}$ and Hertfordshire follow-up study. ${ }^{41}$ Nonetheless, our finding is inconsistent with other Chines famine study. ${ }^{18}$ These variations could be explained by the heterogeneity of test tools. Comprehensive neuropsychological tests, containing the Telephone Interview of Cognitive Status-10, word recall and pentagon drawing was used to estimate cognitive performance in Chinese study, ${ }^{18}$ as MoCA was used in Ethiopian study.

The presents study finding has implications for the global rise of neurodevelopmental problems. It adds for understanding of the links between early life and later health, and examines the role of nutrition in utero and postnatal life in the aetiology of decreasing cognitive function in later life. More remarkably, these findings are used to plan effective ways of improving cognitive function of adults in Ethiopia, a country known for high prevalence of malnourishment during early life. ${ }^{37}$ Additionally, these findings may help policy-makers to establish context-specific strategies particular to famine prone regions of the country.
There are several limitations of our study. First, the findings might be partly biased by survival bias. It is plausible that potential participants could not participate because of health-related problems, and others may have already died due to the exposure. Second, exposure to the famine was defined using the self-reported birth date and age; thus, recall bias cannot be ruled out. However, it is at our utmost belief that the exceptional catastrophic period of the famine, named as 'Evil Days' in the memory of the survivors and the world could not be forgettable. Third, severity of exposure at individual level was not considered although the long-term consequence of famine depends on the severity of the exposure within the household. Fourth, the study did not capture early childhood experiences such as parent-child bond, parenting style and neonatal problems such as asphyxia, hypoglycaemic, hypothermia, preterm, which causes brain damage and predispose to reduced cognitive function in later life. Finally, reduced in cognitive function could be worsening with age. However, the prolonged Ethiopian great famine affected almost the whole Ethiopia, ${ }^{21}$ making it impossible to identify a control group that was not affected by famine. To overcome this limitation, age adjustment was conducted in the multivariable model. Despite all these limitations, our study is the first to investigate long-term consequences of early life exposure to famine in the context of low-income countries like Ethiopia.

In conclusion, famine exposure during early life was positively associated with cognitive function in adults. More specifically, postnatal famine exposure was associated with decreased cognitive function. Although there was no statistically significant association between prenatal exposure to famine and cognitive function in adults, a decrease in cognitive test score was observed. The study will potentially lead to better nutritional interventions during intrauterine period and the first 2 years of postnatal life. The mechanism through which famine exposure during early life influenced adult cognitive function needs additional study in a similar context.

\section{Author affiliations}

${ }^{1}$ Nutrition and Dietetics, Debre Tabor University, Debre Tabor, Ethiopia

${ }^{2}$ Nutrition and Dietetics, Jimma University College of Public Health and Medical

Sciences, Jimma, Ethiopia

${ }^{3}$ Psychiatry, Jimma University College of Public Health and Medical Sciences, Jimma, Ethiopia

${ }^{4}$ Obstetrics and Gynecology, Jimma University College of Public Health and Medical Sciences, Jimma, Ethiopia

${ }^{5}$ Department of Population and Family Heath, Jimma University College of Public Health and Medical Sciences, Jimma, Ethiopia

Acknowledgements The authors would like to acknowledge the Institute of Health, Jimma University for funding the study. The authors are also grateful to the study participants for their dedicated time and volunteer participation.

Contributors GA, KH and MA conceived and planned the study and did the analysis and interpretation. GA implemented and supervised the field work. FA and MA were involved in data cleaning and verification. GA, FA and MA drafted the manuscript. MA, KH, TB and MA critically revised the manuscript. All authors have reviewed the manuscript and approved the final version for submission.

Funding The study was funded by Jimma University, Institute of Health. 
Competing interests None declared.

Patient and public involvement Patients and/or the public were not involved in the design, or conduct, or reporting, or dissemination plans of this research.

Patient consent for publication Not required.

Ethics approval Ethical approval was obtained from Institutional Review Board of Jimma University (Ref. No. JHRPGD/660/2019).

Provenance and peer review Not commissioned; externally peer reviewed.

Data availability statement Data are available upon reasonable request.

Open access This is an open access article distributed in accordance with the Creative Commons Attribution Non Commercial (CC BY-NC 4.0) license, which permits others to distribute, remix, adapt, build upon this work non-commercially, and license their derivative works on different terms, provided the original work is properly cited, appropriate credit is given, any changes made indicated, and the use is non-commercial. See: http://creativecommons.org/licenses/by-nc/4.0/.

ORCID iD

Getachew Arage http://orcid.org/0000-0003-4155-3237

\section{REFERENCES}

1 Bhatnagar S, Taneja S. Zinc and cognitive development. Br J Nutr 2001;85 Suppl 2:S139-45.

2 Richards M, Shipley B, Fuhrer R, et al. Cognitive ability in childhood and cognitive decline in mid-life: longitudinal birth cohort study. BMJ 2004;328:552

3 BNF. Nutrition and development: short and long term consequences for health. Task force report, 2013.

4 Bryan J, Osendarp S, Hughes D, et al. Nutrients for cognitive development in school-aged children. Nutr Rev 2004;62:295-306.

5 Georgieff MK. Nutrition and the developing brain: nutrient priorities and measurement. Am J Clin Nutr 2007;85:614S-20.

6 Fox SE, Levitt P, Nelson CA. How the timing and quality of early experiences influence the development of brain architecture. Child Dev 2010;81:28-40.

7 Chisholm D, Heslin M, Docrat S, et al. Scaling-up services for psychosis, depression and epilepsy in sub-Saharan Africa and South Asia: development and application of a mental health systems planning tool (OneHealth). Epidemiol Psychiatr Sci 2017;26:234-44.

8 Whiteford HA, Ferrari AJ, Degenhardt L, et al. The global burden of mental, neurological and substance use disorders: an analysis from the global burden of disease study 2010. PLoS One 2015;10:e0116820.

9 Naghavi M, Global NM, Global Burden of Disease Self-Harm Collaborators. Global, regional, and national burden of suicide mortality 1990 to 2016: systematic analysis for the global burden of disease study 2016. BMJ 2019;364:194

10 Mulugeta T, Dessalegn M, Behailu S. Cognitive impairment among type 2 diabetes mellitus patients in Ethiopia. International Journal Of Medical And Applied Sciences 2013;2:40-54.

11 Dagnew B, Wolide AD, Mossie A. Cognitive impairment among type 2 diabetes mellitus patients at. Southwest Ethiopia: Jimma University Specialized Hospital, 2017.

12 Debalkie Animut M, Sorrie MB, Birhanu YW, et al. High prevalence of neurocognitive disorders observed among adult people living with HIV/AIDS in southern Ethiopia: a cross-sectional study. PLoS One 2019;14:e0204636.

13 Barker DJP. The developmental origins of adult disease. J Am Coll Nutr 2004;23:588S-95.

14 Schlotz W, Phillips DIW. Fetal origins of mental health: evidence and mechanisms. Brain Behav Immun 2009;23:905-16.

15 Gluckman PD, Hanson MA, Cooper C, et al. Effect of in utero and early-life conditions on adult health and disease. N Engl J Med 2008;359:61-73.

16 Wang C, An Y, Yu H, et al. Association between exposure to the Chinese famine in different stages of early life and decline in cognitive functioning in adulthood. Front Behav Neurosci 2016;10:146.

17 Xu H, Zhang Z, Li L, et al. Early life exposure to China's 1959-61 famine and midlife cognition. Int $J$ Epidemiol 2018;47:109-20.

18 Rong H, Lai X, Mahmoudi E, et al. Early-Life exposure to the Chinese famine and risk of cognitive decline. J Clin Med 2019;8:484.

19 de Rooij SR, Wouters H, Yonker JE, et al. Prenatal undernutrition and cognitive function in late adulthood. Proc Natl Acad Sci U S A 2010;107:16881-6.

20 Rong H, Xi Y, An Y, et al. The correlation between early stages of life exposed to Chinese famine and cognitive decline in adulthood: nutrition of adulthood plays an important role in the link? Front Aging Neurosci 2017:9:444.

21 Dercon S, Porter C. Live aid revisited: long-term impacts of the 1984 Ethiopian famine on children. J Eur Econ Assoc 2014;12:927-48.

22 Rahmato D. Famine and survival strategies: a case study from northeast Ethiopia. Nordic Africa Institute, 1991.

23 Arage G, Belachew T, Hassen $\mathrm{H}$, et al. Effects of prenatal exposure to the 1983-1985 Ethiopian great famine on the metabolic syndrome in adults: a historical cohort study. Br J Nutr 2020:1-9.

24 Julayanont $\mathrm{P}$, Tangwongchai S, Hemrungrojn S, et al. The Montreal cognitive Assessment-Basic: a screening tool for mild cognitive impairment in Illiterate and Low-Educated elderly adults. J Am Geriatr Soc 2015;63:2550-4.

25 Rodríguez MM, Méndez $\mathrm{H}$, Torún $\mathrm{B}$, et al. Validation of a semiquantitative food-frequency questionnaire for use among adults in Guatemala. Public Health Nutr 2002;5:691-8.

26 Lee LK, Shahar S, Chin A-V, et al. Prevalence of gender disparities and predictors affecting the occurrence of mild cognitive impairment (MCl). Arch Gerontol Geriatr 2012;54:185-91.

27 Zhang N, Yang Y, Wang A, et al. Association of ideal cardiovascular health metrics and cognitive functioning: the APAC study. Eur $J$ Neurol 2016;23:1447-54.

28 Kretchmer N, Beard JL, Carlson S. The role of nutrition in the development of normal cognition. Am J Clin Nutr 1996;63:997S-1001.

29 Meaney MJ, Szyf M, Seckl JR. Epigenetic mechanisms of perinatal programming of hypothalamic-pituitary-adrenal function and health. Trends Mol Med 2007;13:269-77.

30 Lagali PS, Corcoran CP, Picketts DJ. Hippocampus development and function: role of epigenetic factors and implications for cognitive disease. Clin Genet 2010;78:321-33.

31 Peter CJ, Fischer LK, Kundakovic M, et al. Dna methylation signatures of early childhood malnutrition associated with impairments in attention and cognition. Biol Psychiatry 2016;80:765-74.

32 Sgarbieri VC, Pacheco MTB. Human development: from conception to maturity. Braz J Food Technol 2017;20.

33 Georgieff MK. Early brain growth: macronutrients for the developing brain. Neoreviews 2006;7:e334-43.

34 Walker SP, Wachs TD, Gardner JM, et al. Child development: risk factors for adverse outcomes in developing countries. Lancet 2007;369:145-57.

35 Berkman DS, Lescano AG, Gilman RH, et al. Effects of stunting, diarrhoeal disease, and parasitic infection during infancy on cognition in late childhood: a follow-up study. Lancet 2002;359:564-71.

36 Crookston BT, Dearden KA, Alder SC, et al. Impact of early and concurrent stunting on cognition. Matern Child Nutr 2011;7:397-409.

37 Rahman A. Prevalence and determinants of chronic malnutrition among under-5 children in Ethiopia. Int $J$ Child Health Nutr 2013:2:230-6.

38 Everson-Rose SA, Mendes de Leon CF, Bienias JL, et al. Early life conditions and cognitive functioning in later life. Am J Epidemiol 2003;158:1083-9.

39 Ampaabeng SK, Tan CM. The long-term cognitive consequences of early childhood malnutrition: the case of famine in Ghana. J Health Econ 2013;32:1013-27.

40 de Groot RH, Stein AD, Jolles J, et al. Prenatal famine exposure and cognition at age 59 years. Int J Epidemiol 2011;40:327-37.

41 Martyn CN, Gale CR, Sayer AA, et al. Growth in utero and cognitive function in adult life: follow up study of people born between 1920 and 1943. BMJ 1996;312:1393-6. 